\title{
FUNDAMENTOS PARA LA EDUCACIÓN EN LA PAZ
}

Ana Teresa López de Llergo

\section{RESUMEN}

LOS FUNDAMENTOS PARA LA EDUCACIÓN EN LA PAZ, PRESENTADOS EN este texto, surgen de un estudio ${ }^{1}$ en el que se vincula la paz con los valores y las virtudes. Se complementa con un planteamiento donde se indican los medios para alcanzarla, tanto en el interior de la persona como en las relaciones con quienes la rodean.

\section{ABSTRACT}

The foundation for education in peace, as setin this text, comes up from a study in which there is a connection among peace, values and virtues. Itis complemented with a proposal in which the means to reach it are pointed out, in the innermost of the individual as in the relations that surround him.

\section{INTRODUCCIÓN}

Cada vez es más apremiante la necesidad de viviren paz y, al mismo tiempo, ese anhelo parece ser un ideal inalcanzable. Muchas veces, los proyectos educativos buscan resultados inmediatos y fáciles, por medio de recetas simplistas; nos olvidamos de que las respuestas que así se obtienen carecen de raíz y desaparecen cuando hay dificultades. Lo que perdura sobre la prueba del cansancio o del desánimo, eso sí, es sólida construcción de una personalidad madura.

En este trabajo, el fundamento en la educación para alcanzar la paz consiste en vincularla con el valor originario de la belleza, con los valores humanos de la intimidad y la comunicabilidad, y con los valores relacionales del respeto y de la lealtad. Después, se relaciona 
la paz con la virtud intelectual de la ciencia y con las virtudes morales del orden, lajusticiay la templanza. De este modo pueden surgir iniciativas que faciliten el perfil de hombres y mujeres con espíitu de armonía.

Con base en estos postulados, se realiza un planteamiento educativo que incida en el fomento de las virtudes citadas; la oportunidad y losmedios para promoverlas se deja al sentido común de los educadores, quienes han de apoyarse en las caracteństicas del educando.

\section{NOCIÓN DE PAZ}

Agustín de Hipona señala que la paz es tranquilidad en el orden. La paz del cuerpo es el orden de sus partes. La paz del alma racional es la ordenada armonía entre conocimiento y acción. La paz del almay del cuerpo es la vida ordenada y la salud. La paz del hombre con Dios es la obediencia ordenada por la fe bajo la ley etema. La paz de los hombres entre sí es su ordenada concordia. La paz en la casa es la ordenada concordia entre los que mandan y obedecen. La paz de la ciudad es la ordenada concordia entre los que gobieman y los gobernados. La paz de todas las cosas es la tranquilidad del orden. El orden es la disposición que asigna a las cosas diferentes, y a las iguales, el lugarque les comesponde 2 .

La paz posee dos dimensiones. La interior, se instala en la persona y produce tranquilidad, denivada del esfuerzo porcuidarla salud de cuepo y alma, mediante la coherencia de vida (armonizarlas pasiones con los conocimientos y responsabilidades).

La extenior, se basa en el modo de asumir la relación con Diosy de fomentar buenas relaciones con los semejantesy con la naturaleza. El pacífico abre las inteligencias y los corazones de los demás; evita la ofuscación y promueve la búsqueda de lo que une; establece la articulación entre las tendencias de las propias pasiones y las ponderadas decisiones de la voluntad.

Lapaz enriquece la intimidad y la comunicabilidad de las personas. La intimidad, porque contramesta la tendencia al egoísmo, evita 
los pensamientos y deseos injustos, descarta la competitividad deshonesta, el afán de aprovecharse de los demás, la desconfianza o las envidias ${ }^{3}$.

La comunicabilidad, porque se logra un auténtico diálogo con los demás pues existe una actitud comprensiva ante las diferencias, buscando soluciones que beneficien a todos sin claudicar a los propios principios. Aunque la actitud ha de ser realista pues «el diálogo es a menudo difícil, porque sobre él pesa la hipoteca de trágicas herencias de guerras, conflictos, violencias y odios, que la memoria sigue fomentando. Para superar las barreras de la incomunicabilidad, el camino a recorrer es el del perdón y la reconciliación».

La paz requiere colaboración mutua pero no siempre concuerda el deseo y la intensidad de unos y otros para luchar por ella. Sin embargo, como es un anhelo de todos, hay que mantenerviva la esperanza poralcanzarla.

\section{LA PAZ Y LOS VALORES 5}

Como dij̈mos, los valores humanos que pueden darse en plenitud y armonía con la paz, son la intimidad y la comunicabilidad. Esto demanda un buen uso de la libertad cuya consecuencia es la quietud interiory exterior, que no significa ni apatía ni pasividad. Así, pueden fomentarse los valores relacionales del respeto y de la lealtad.

Con la paz se logra un equilibrio que conserva la intimidad de cada uno y la del grupo social sin que existan tensiones, pues no hay peligro de gregarismo o de masificación. Así, se logra la estabilidad que no resiste alteraciones bruscas sin grave riesgo de estropear la identidad personal y por eso, el deterioro en las relaciones humanas ${ }^{6}$. Como la paz incluye orden, esposible diseñaruna plenitud exenta de comparaciones o envidias, se puede hablarde conservarsin conformismos. En la armonía conseguida se manifiesta con clanidad el valoroniginanio de la belleza, que sintetiza el bien y la verdad.

El educador ha de fomentar el equilibrio entre intimidad y comunicabilidad; respeto y lealtad que evitan el hermetismo, la in- 
discreción, la discordia, la traición, etcétera. Esto, desde luego, no es fácil pero, cuando se logra, cada miembro de una sociedad se integra racionalmente, ligado porla concordancia de fines amados; de manera que para saber qué es una comunidad es preciso examinarlos objetos de su amory será tanto mejor cuanto más nobles sean los intereses que unen, y tanto peor cuanto menos nobles sean?

Como la paz se deriva del recto amor, conviene recordar lo siguiente:

Dosamoresfundaron, pues, dosciudades, a saber: el amorpropio hasta el desprecio deDios, la terrena, y el amor deDioshasta el desprecio desí propio, la celestial. La primera busca la gloria delos hombres, seengríe, susgobernantessedejan llevar porla concupiscencia del poder, seobscurecen loscorazones, seengallan en susconocimientosy caen en la soberbia, rinden culto a lascriaturas. En la segunda sebusca la gloria deDioscomo testigo dela conciencia, hay caridad y por resolosgobernantesaconsejan y lossúbditosobedecen, aman a Dioscomo a su fortaleza, no hay sabiduría humana sino piedad, seda cultoa Diosyseespera el premio en la sociedad delos santos.

En este texto se vuelve a descubrir el valor oniginario de la belleza entendida como armonía, plenitud y por tanto quietud, porque no hay afán poralcanzaralgo más, pues ya se está en la meta.

\section{LA PAZ Y LAS VIRTUDES 9}

La ciencia es la virtud intelectual que vinculamos con la paz, porque facilita el conocimiento personal y de los demás; descubre también la armonía que debe habero las deficiencias para extimparlas. De esta manera, la inteligencia se capacita para plantear vías de acción que el serhumano pueda recomerpara superarse.

El orden - personal y social - es otra virtud que conserva la paz al propiciar un buen ambiente dentro y fuera de sí. Cuando se capta bien el sentido de las relaciones humanas y la importancia de que no 
se deterioren, nos percatamos que también es necesania la virtud de la justicia, valuarte de la paz. Puede concebirse la sociedad como el ámbito en que se valoran y promueven tres características que mutuamente se exigen y potencian. La primera y más radical es, sin duda, el protagonismo de las personas humanas reales y concretas, que toman conciencia de su condición de miembros activos y responsables de la sociedad y procuran participar eficazmente en su configuración política. La segunda es la consideración de las comunidades humanas - en sus diferentes niveles- como ámbitos imprescindibles y decisivos para el pleno desamollo de las mujeres y los hombres que las componen; en ellas se superan las actitudes individualistas, para actuarcomo ciudadanos pulsados por derechos intocablesy por deberes irrenunciables. Porúltimo, se concede un alto valor a la esfera pública, precisamente porque resulta el ámbito de despliegue de las libertades sociales y como instancia de garantía para que la vida de las comunidades no sufra interferencias indebidas ni abusivas presiones de poderes ajenos a ellas ${ }^{10}$.

La templanza es otra una virtud que logra la amonía y la serenidad interior, propicia la conservación de la paz, y hace posible las buenas relaciones desafiando los embates de las tendencias al propio placeren detrimento del servicio alos demás. Nunca se ha de acabarcon rompimiento, ya sea amistad, ya sea favor, empleo o cargo, que toda quiebra ofende la reputación, además de la pena que causa»1.

\section{PLANTEAMIENTO EDUCATIVO}

El amor ha de informara la paz pues así se facilita superar obstáculos personales. Por ejemplo, la ruptura establecida entre la inteligencia, que ve con claridad sus beneficios, y la falta de voluntad para poner los medios adecuados, en ocasiones complicados porel recuerdo de ofensas o desavenencias que desordenan. Además, construirla paz no depende sólo de uno, hace falta la buena voluntad de los otrosy, muchas veces, no es fácil conocer sus intenciones pues algunos aparentan buena voluntad cuando realmente no la tienen. 
Por ello, hay que formar los corazones para evitar altibajos y lograrla ecuanimidad. Todos buscan la paz como un fin, pero el problema para alcanzarla se debe a que cada uno quiere indicar cómo debe sery, buscándola, se propician las disensiones.

Se han hecho intentos de sistematizar las diversas manifestaciones de la paz: personal (interior) y social. Sin embargo, la paz y la guema coexisten. Para explicámoslo debemos distinguir entre la paz del mundo - cuando no existe ningún conflicto y se extiende a todo el universo- y la paz en el mundo, cuando en algunos sitios hay paz y en otros no. La guema puede entenderse como un sistema temporal que se inicia con un fin determinado y se acaba cuando éste se alcanza. Los mencionados campos de la paz se pueden considerar como un continuo que va desde la paz interior hasta la de mayor extensión: la paz universal y mundial ${ }^{12}$.

Los educadores han de fomentar la observación y el reconocimiento de los valores en sí y en los demás, mediante el ejercicio de la virtud de la ciencia. Para ello, tomando en cuenta la edad y las caracteństicas personales, ayudarán a examinar lo que conforma la intimidad - muchas veces lastimada por malas experiencias- y han de descubrir, con caridad, esas deficiencias y procurar restañar henidas para facilitarel diálogo, condición de la paz.

Otro aspecto importante es saliral paso al desorden que causa no perdonar, entendiendo que pueden existirmotivos de lesiones físicas o psíquicas que al serrecordadas vuelven a herir. El primerpaso es tratar de disculpar a quien ocasionó tales heridas, y mientras se logra el olvido hay que sobrellevar, con buen talante, el dolor que aún perdura en la memoria. Ayuda pensarque muchas veces uno, también, ha ocasionado tales problemas.

Con respecto al orden debe enseñarse que cada quien tiene un papel que desempeña en la so ciedad, ya sea porlas aptitudes poseídas o por los compromisos asumidos, y aunque no sea fácil responder, hay que esforzarse. Por otro lado, también dificulta el orden la inadecuada organización social que muchas veces ofrece cargos de 
autoridad a quienes no la tienen y viceversa. Ante esto necesitamos abrimos a la comprensión, porque no existe sociedad perfecta aunque se desee constituirla.

La justicia tan claramente buscada en la infancia, muchas veces ni en ella se vive bien, poreso, desde temprana edad hay que enseñar a dara cada uno lo que le comesponde y a no quitarle aquello que ha adquirido rectamente.

La templanza es una virtud que incide directamente en el orden intenior, por eso es vital enseñar a adquirir una voluntad firme que no se deje llevarpor la ley del mínimo esfuerzo o porla comodidad. Y como se tiende a la comodidad, enseñar a privarse de pequeños satisfactores lícitos lleva a fortalecer la voluntad.

$\mathrm{Al}$ incidir en el ejercicio de las virtudes se consigue respetar los valores.

\section{REFERENCIAS BIBLIOGRÁFICAS}

${ }^{1}$ LÓPEZ DELERGO, A.T., Educación en valores, educación en virtudes., p.45 a 46, 95 a 96, 145 a 147.

${ }^{2}$ Cfr. DE HIPONA, A., La ciudad de Dios., XIX, 13,1.

${ }^{3}$ JUAN PABLO II., Novo millennio ineunte., n. 43.

${ }^{4}$ JUAN PABLO II., Diálogo entrecultura, condición para la paz., n. 21.

${ }^{5}$ Porvalor entendemos ła perfección real o posible que procede de la naturaleza y que se apoya tanto en el ser como en la razón de serde cada realidad»(Cfr., LÓPEZ DE LERGO, A.T., Valores, valoracionesy virtudes., p.34).

${ }^{6}$ Cfr. DE HIPONA, A., Op.cit., XIX p.32.

${ }^{7}$ Cfr. Ibidem., XIX., 24.

${ }^{8}$ Idem., XIV., 28.

${ }^{9}$ Virtud es un hábito operativo bueno.

${ }^{10}$ Cfr. LUANO, A., Humanismo cívico., p.15.

${ }^{11}$ GRACIÁN, B., El discreto., p.29.

${ }^{12}$ Cfr. Pedagogía visibleyeducación invisible., p.150-152. 


\section{BIBLIOGRAFÍA}

DE HIPONA, Agustín., La ciudad de Dios., Biblioteca de Autores Cristianos., Madrid., 1958., 1728 p.

GARCÍA HOZ, Víctor., Pedagogía visibley educación invisible., Ediciones Rialp., S.A., Madrid., 1987., 216 p.

GRACIÁN, Baltasar., El discreto, El criticón, El héroe., 2ª edición., Editorial Pomúa., S.A., México., 1986., 399 p.

JUAN PABLO II:

Novo millennio ineunte., Arquidiócesis Primada de México., 2001., 57 p.

Diálogo entreculturas, condición depaz., Mensaje para la Jomada Mundial de la Paz., ZENIT., 14 de diciembre de 2000., 10 p.

¿ANO, Alejandro., Humanismo cívico., Ed. Ariel., S.A., Barcelona., 1999., $188 \mathrm{p}$.

LÓPEZ DE LLERGO, Ana Teresa:

Valores, valoracionesy virtudes., CECSA., Patria Cultural., México., 1999., $206 \mathrm{p}$.

Educación en valores, educación en virtudes, Tesis de Maestría en Pedagogía., Universidad Panamericana., México., 2001., 187 p. 